learned, the team says, by interviewing those involved in the decisions (like Sir Alec Merrison and Sir Denys Wilkinson in the case of Rutherford and Daresbury and Sir Martin Ryle in the case of Mullard), from published sources (in the case of CERN) and if possible through access to original documents.

But the team is likely to face a critical problem over access to SRC documents. When Mike Gibbons and John Hartland did their study of CERN for the old Council of Scientific Policy (CSP) -a study the team mentions-the SRC gave special dispensation because the study was confidential to the Council; when Margaret Gowing sought SRC documents for her study of CERN on behalf of CERN, the SRC was prepared to allow access but the Department of Education and Science refused under the thirty-year rule. On that history, access is likely to be denied to the SPRU researchers.

The team does not see possible denial of access as a special difficulty. But Gibbons thinks otherwise. Not only did it take him and Hartland two years to do their study, which was of one centre, not six plus two new ones; they also found the original documents essential in providing what he calls a "well constructed net", the holes of which could be plugged with the help of interviews. Only with the documents could they appreciate just how much memories failed with time and how beneficial hindsight could be.

Whether or not the research yields controversial findings, the fact that it is going ahead at all has certainly provoked interest. The SSRC has some $£ 25,000$ at its disposal for science policy studies; this used to be in the hands of the CSP but was transferred to the SSRC when the Advisory Board for the Research Councils (ABRC) began. This award to the SPRU team means that other applications are denied. That is nothing new, except that, in going to one large project, it is ironically favouring 'big science policy' proposals at the expense of others whose merit may be as clear. More interestingly, and particularly as the research is about the SRC, the SRC is certain to have seen a copy of the proposals at an early stage and to have passed a verdict on it.

Two factors indicate why the SRC might be unhappy about it. One is the precedent of the Gowing case: lack of access is bound to reduce the value of the research. The other is its natural misgivings about the quality and partiality of science policy research, using anecdotal evidence or not. Indeed, Norman Dombey's own article on CERN, in The Times Higher Education Supplement earlier this year, is unlikely to have endeared this project to the SRC. And Keith Pavitt's views on the use to which Britain's scientists and engineers are put (typically, into aircraft, nuclear reactors and weapons instead of motor cars and machinery) won't have helped.

The topicality of the subject may have assisted the SSRC in reaching a decision. But one suggestion being put about last week, which could not be confirmed, was that the SSRC's political science committee regards its support for the SPRU proposal as a test case in its efforts to establish itself as the body sponsoring research that monitors decisions in government. The project, it was suggested, is a useful addition to the pressure for a lifting of the thirty-year rule.

As far as Dr Saul Rose, the committee's chairman, is concerned, there are bound to be differing views of its support for the project, as there are for much of the work it sponsors. As for projects that could "come up against a stone wall" because of lack of access, it was always hoped that something could be worked out; in any case projects were monitored, and could be called off or perhaps reshaped if they were unlikely to achieve the intended aims.

In the end, though, the project will be judged by its results. No one wanted to anticipate those last week, or to predict their likely impact. But one former high energy physicist privately expressed his reservations. The big science community in Britain, he said, was now highly sensitive to criticism after the financial battering of recent years. Though prepared to admit that the findings might be interesting, he couldn't see what useful purpose the project would ultimately serve.

\title{
Reactor choice: last lap looms
}

THE final and most important phase of Britain's tortuous debate over which type of thermal nuclear reactor should follow the existing Magnox generation is just beginning. Last week the Department of Energy (DEN) published extracts from the assessment made over the past nine months by the National Nuclear Corporation (NNC) of the three thermal reactor systems under scrutinythe Pressurised Water Reactor (PWR), the Advanced Gas-Cooled Reactor (AGR) and the Steam Generating Heavy Water Reactor (SGHWR).

At the same time the Health and Safety Executive published an account from its Nuclear Installations Inspectorate (NII), responsible for nuclear safety, of its study of the generic safety issues of PWRs. And the DEN also made available a summary of the discussions on nuclear energy policy which emerged at the closed weekend seminar it held in May.

The nuclear industry, the customers the politicians and others are expected to digest the contents of the massive NNC and NII volumes during a quiet August; discussions in September may then allow the matter to be put before the Cabinet for collective decision sometime in October. Mr Anthony Wedgwood Benn, the Secretary of State for Energy, for one, is looking forward to an interesting debate.

The NNC report says a decision has to be taken now both about the reactor systems and about actual orders "if the nuclear power option is to be maintained in a meaningful way". It says categorically that "there is no case for the adoption of the SGHWR" because there could be no operational experience of commercial sizes for a decade, there is no chance of exports and it is the most costly of the three.

Over the PWR and AGR, the report offers three options: continue with AGR, do not adopt PWR; adopt PWR, finish the current AGR programme but don't add to it; and adopt PWR, continue with AGR. The NNC says it cannot advise the first course because it would be rejecting important export opportunities; to be grasped, moreover. these require a decision now. The second course, it says, would help exports and lead to "the cheapest available electric power for Britain", but construction of the first PWR could only start in 1980; for the course to be acceptable, ways must be found of "maintaining the confidence and enthusiasm" of those laid off by the lack of AGR work.

The third course offers the advantage of keeping open an option, but has the disadvantage of dividing available resources. "In practice", the report suggests, "it is not likely to be sensible to maintain an ordering programme for two systems beyond the early 1980s". The summary concludes that the early adoption of the PWR would have to be supported by a domestic ordering programme of more than one reactor, and that an AGR station would have to be ordered and built, if the purposes of the choice are to be achieved.

The choice of thermal reactor was also the subject of a session at the nuclear policy seminar. Although Sir Alan Cottrell, former government science adviser, disagreed, both Ned Franklin of the NNC and Walter Marshall, the DEN's former chief scientist, thought safety arguments were not a significant factor in the choice, a point borne out by the NII report, which concludes that "there is no fundamental reason for regarding safety as an obstacle" to choosing the PWR.

One interesting contribution to the seminar came from Sir Hermann Bondi, however, whose appointment to the DEN's as chief scientist was confirmed last week. It was very likely, he said, that the first major acoident would be with a PWR because of their widespread adoption; there could be some advantage he said, in being outside the main stream. As in the NNC report, the seminar summary also reveals clearly the importance attached to the matter of exports in reaching a decision.

Chris Sherwell 